\title{
Design of 3-stage Parallel Cascade Micro-ring Resonator Type of Interleave Filter for Optical Communication Application
} Desain dari Filter Interleave jenis Parallel Cascaded
Microring Resonator 3 tingkat
untuk Aplikasi Komunikasi Optik

\author{
Yudi Yuliyus Maulana* and Dadin Mahmudin \\ Research Center for Electronics and Telecommunication - Indonesian Institute of Sciences (LIPI) \\ Komplek LIPI Gedung 20 Lantai 4, Jl Sangkuriang, Bandung 40135, Indonesia
}

\begin{abstract}
Abstrak
Filter will be one of the most important components of the next generation of optical communications. Micro-ring resonators have been widely studied as a potential device for dense wavelength filter due to its advantages. In this paper, a waveguide-based microring-resonator type of interleave filter is investigated. The cascade structure is applied to obtain better characteristics of filter spectra. Our calculation shows that, compared with 2-stage or 4-stage cascade, 3-stage cascaded microring resonator has better performance with pass-band width of $22 \mathrm{GHz}$, ripple ratio $<1 \mathrm{~dB}$, crosstalk of $-33 \mathrm{~dB}$ for $1 \times 2$ interleaver and $-24 d B$ for $1 \times 4$ interleaver. Numerical calculation also clearly shows that general optical waveguide types is reasonable as microring resonator with insertion loss $<2 d B$.
\end{abstract}

Keywords: interleave filter, wavelength splitter, microring resonator.

\section{Abstract}

Komponen filter merupakan komponen yang sangat penting untuk aplikasi sistem komunikasi optik di masa yang akan datang. Micro-ring resonator telah dipelajari secara luas sebagai devais yang mempunya potensi sebagai filter karena kelebihankelebihannya. Dalam makalah ini telah diteliti filter interleave tipe Parallel Cascaded Micro-ring Resonator (PCMR). PCMR merupakan struktur Micro-ring resonator yang terdiri beberapa ring disusun secara paralel dengan tujuan untuk memperoleh karakterisasi terbaik. Dari hasil perhitungan memperlihatkan bahwa dibandingkan dengan PCMR dengan 2 ring dan PCMR dengan 4 ring, PCMR dengan 3 ring mempunyai performa yang lebih baik dengan lebar pass-band sebesar 22 GHz, ripple ratio $<1 \mathrm{~dB}$, crosstalk sebesar $-33 \mathrm{~dB}$ untuk $1 \times 2$ interleaver dan $-24 \mathrm{~dB}$ untuk $1 \times 4$ interleaver. Dari perhitungan numerik dengan jelas memperlihatkan bahwa umumnya jenis optical waveguide adalah wajar sebagai micro-ring resonator yang mempunyai nilai insertion loss $<2 \mathrm{~dB}$.

Kata kunci: filter interleave, wavelength splitter, micro-ring resonator.

\section{INTRODUCTION}

Explosive growth in the internet requires larger channel capacity. Dense wavelength-division multiplexing (DWDM) is an important solution for this demand. This growth requires high performance of optical devices. One of key devices for DWDM is wavelength filter. Recently, DWDM has had channel spacing narrower than $100 \mathrm{GHz}$. In order to satisfy this requirement, waveguide-based filters are proposed. A concept of interleave filter or interleaver (or wavelength splitter) was also introduced to DWDM system with channel spacing $<50 \mathrm{GHz}$ using Mach-Zhender Interferometer [1]. In addition to the type of MZI, there are several types of filters are investigated in the past few years such as array wave guide (AWG), Fiber Brag

* Corresponding Author.

Email: yudiym@gmail.com

Received: November 18,2015; Revised: November 28, 2015

Accepted: December 5, 2015

Published: December 30, 2015

(C) 2015 PPET - LIPI

doi : 10.14203/jet.v15.66-70
Grating (FBG), Fabry-Perot Interferometer (FPI) etc. [2].

Micro-ring resonators (MRR) have been widely studied as a potential device for communication applicatios due to its advantages in smaller size and can be integrated with other devices [3]. The other advantage of the MRR is easily modified into another form (structure of MRR) to increase the performance. Therefore, in addition to communication applications, MRR can be used for sensor applications with a high level of sensitivity [4], [5].

In this paper, our investigation of interleaver by using cascaded microring resonator is reported. Since microring resonators have 2 outputs, i.e. resonance output and antiresonance output, and also have periodic spectrum characteristics, they are applicable for interleavers. Another advantage of a microring resonator inter leaver is that the denser DWDM channel will require larger ring radius. As a result, bending loss is negligible because the bending loss decreases with increasing ring radius. Based on optical lattice structure 
theory [6], the cascade structure is provided to obtain better characteristics.

\section{DEVICE MODELING}

Figure 1 (a) shows an example of 3-stage cascade of micro-ring resonator with ring radius $r$. Out-1 and Out-2 are anti resonance and resonance outputs, respectively. In 12 interleavers, one outport is used to passthrough odd channels and the other port passthroughs even channels. Figure 1 (a) illustrates that resonance wavelength is set to even channels.

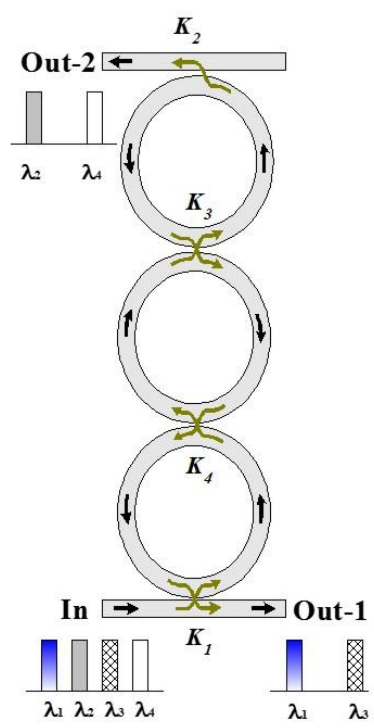

(a)

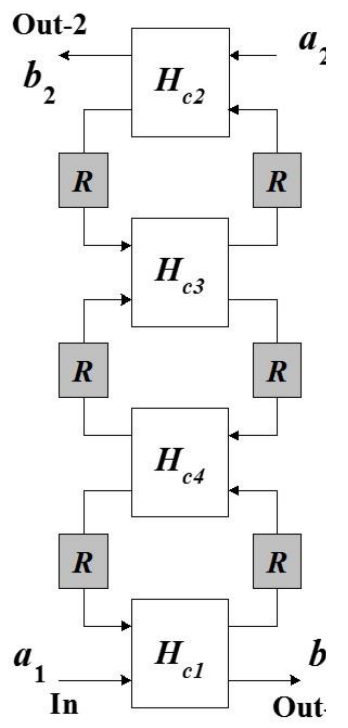

(b)
Figure 1. (a) 3-Stages Cascade Micro-ring Resonator Structure, (b) Block Diagram for Our Analysis.

Power coupling ratios from input waveguide to ring and from ring to output waveguide are denoted by $K_{1}$ and $K_{2}$, respectively. Power coupling ratios between two rings are denoted by $K_{3}$ and $K_{4}$. The couplings between waveguide and ring, and between two rings are assumed as symmetric directional couplers.

There are some methods to analyze micro-ring resonator. Finite difference time domain (FDTD) method is usually used if both time and space response of fields are required. However, it will consume much memory and calculation time. In this study, since only the steady-state characteristic of microring resonator is needed, transfer matrix method [7], [8] is simpler to be used. Signal flow chart is also applied to derive transfer function of cascaded microring resonator. Figure 1 (b) shows block diagram of 3-stage micro-ring resonator consisting of transfer matrices of directional coupler $H_{\mathrm{c} i}$ (where the subscripts $i=1,2$ are for input and output couplers, and $i=3,4, .$. are for couplers between two rings) and factor of delay lines $R$. Equations of $H_{\mathrm{ci}}$ and $R$ are defined in the following equations:

$$
\begin{gathered}
H_{c i}=\left[\begin{array}{cc}
\sqrt{1-K_{i}} & -j \sqrt{K_{i}} \\
-j \sqrt{K_{i}} & \sqrt{1-K_{i}}
\end{array}\right], \quad i=1,2,3, . . \\
R=e^{-j(\beta+j \alpha) \pi r}
\end{gathered}
$$

where $b, a$, and $r$ are propagation constant, attenuation factor of waveguides and ring radius, respectively. In this analysis we assume that propagation constants of ring and input-output waveguides are same. The waveguides are also assumed as single mode. The excess loss of coupler is also neglected. Figure 1(b) can be expressed in terms of 4-ports network equation as follows:

$$
\left\lfloor\begin{array}{l}
b_{1} \\
b_{2}
\end{array}\right\rfloor=\left\lfloor\begin{array}{ll}
H_{11} & H_{12} \\
H_{21} & H_{22}
\end{array}\right\rfloor\left\lfloor\begin{array}{l}
a_{1} \\
a_{2}
\end{array}\right\rfloor
$$

where $b_{1}, b_{2}$ and $a_{1}$ are complex amplitude of electric field in Out-1, Out-2 and input ports, respectively. In this study $a_{2}$ is zero. The elements of the transfer function $\left(H_{11}, H_{12}, H_{21}\right.$ and $\left.H_{22}\right)$, which a function of $K_{\text {i }}$, $b$, and $a$, can be derived by using signal flow chart. In this paper, evaluating of spectra characteristics is based on the transmittance spectrum of Out-2 (resonance output).

\section{ANAlysis Results}

In general, wavelength filters for DWDM are required to have the following optical characteristics: (1) low channel crosstalk; (2) wide bandwidth with low ripple and box-like spectra; (3) low insertion loss. Assuming LN proton exchange waveguide, our study evaluated those performances of cascaded microring resonator. The FSR of microring resonator is assumed $100 \mathrm{GHz}$. It means that the device works as $1 \times 2$ interleaver for $50 \mathrm{GHz}$ channel spacing.

\section{A. Selection the Values of K1 and K2}

Firstly, we analyzed 2-stage micro-ring in terms of $K_{1}$ and $K_{2}$. Figure 2 shows $-1 \mathrm{~dB}$ bandwidth characteristics and ripple ratio for three values of $K_{1}$ (= $K_{2}$ ) depending on power coupling ratio between two rings $K_{3}$, where $\alpha=0 \mathrm{~dB} / \mathrm{cm}$ is assumed. The ripple ratio is defined as $\mathrm{dB}$ difference between maximum and minimum spectra at top pass-band. We targeted ripple ratio below $1 \mathrm{~dB}$. It is found that for the same value of $K_{3}$, ripple ratio is drastically improved by increasing $K_{1}$ $\left(=K_{2}\right)$. The crosstalk characteristic is shown in Figure 3. Channel crosstalk is expressed as $\mathrm{dB}$ difference between the insertion loss at grid frequency (or wavelength) of channel $\mathrm{n}\left(f_{\mathrm{n}}\right)$ and the insertion loss at respective channel. Crosstalk with respect to the frequency of the channels $\mathrm{n} \pm 1$ is usually termed as "adjacent channel crosstalk". In this paper we use the term "crosstalk" as "adjacent channel crosstalk". For the same value of $K_{3}$,

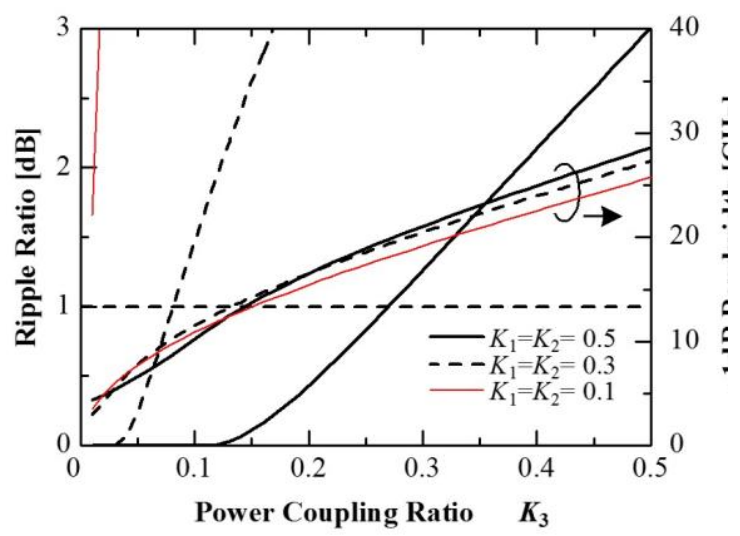

Figure 2. $-1 \mathrm{~dB}$ Bandwidth and Ripple Ratio Characteristics for 2-Stage Cascade Microring Resonator, Attenuation Factor $\alpha=0 \mathrm{~dB} / \mathrm{cm}$. 


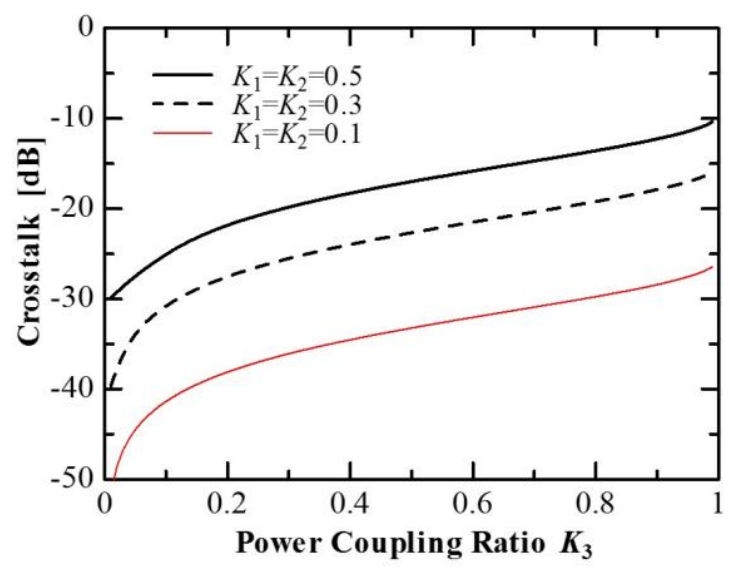

Figure 3. Crosstalk Characteristics for 2-Stage Cascade Microring Resonator $(\alpha=0 \mathrm{~dB} / \mathrm{cm})$

the crosstalk degrades with increasing $K_{1}\left(=K_{2}\right)$. Based on Figure 2 and Figure 3, we choice $K_{1}=K_{2}=0.5$ which shows low ripple with relatively wide pass-band. In the cavity structure, Q-factor will degrade if stored energy in cavity decreases. Increasing $K_{1}\left(=K_{2}\right)$ corresponds to decreasing stored energy in ring resonator. Therefore, we limit $K_{1}=K_{2}$ up to 0.5 . The crosstalk performance can be improved by cascade structure, as it will describe in the next section.

\section{B. Crosstalk Performance}

Since the FSR of the ring is $100 \mathrm{GHz}$, channel crosstalk is calculated between peak level of center frequency (or wavelength) and spectrum level at 50 $\mathrm{GHz}$ separation. Although the value of channel crosstalk should be as low as possible, the target was set to be 25 dB.

Figure 4 shows spectra characteristics for 2-stage, 3 -stage and 4-stage cascade where the spectra level at $50 \mathrm{GHz}$ separation from peak become lower with increasing the number of stages.

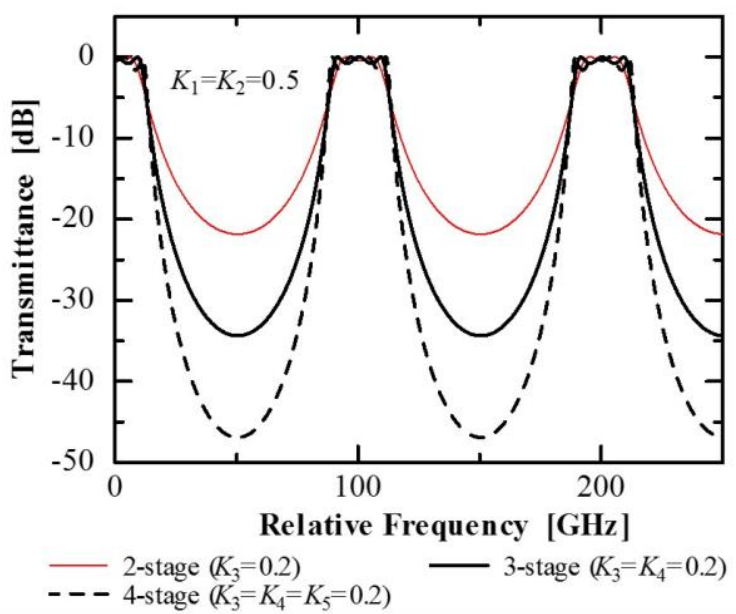

Figure 4. Spectra Characteristics for Various Stages of Cascade Microring Resonator $(\alpha=0 \mathrm{~dB} / \mathrm{cm})$.

Figure 5 shows crosstalk characteristics depending on power coupling ratio between two rings $K_{3}, K_{4}$ and $K_{5}$, which are chosen to be equal each other. Crosstalk degrades with increasing $K_{3}\left(=K_{4}=K_{5}\right)$. For crosstalk of $<-25 \mathrm{~dB}$, we obtain values of $K_{3}\left(=K_{4}=K_{5}\right)$ as follows: (1) $K_{3}<0.1$ for 2-stage structure; (2) $K_{3}\left(=K_{4}\right)<0.48$ for 3-stage structure; (3) $K_{3}\left(=K_{4}=K_{5}\right)<0.71$ for 4 stage structure. These values will be used as references to determine the best choice of the stage number in the next section.

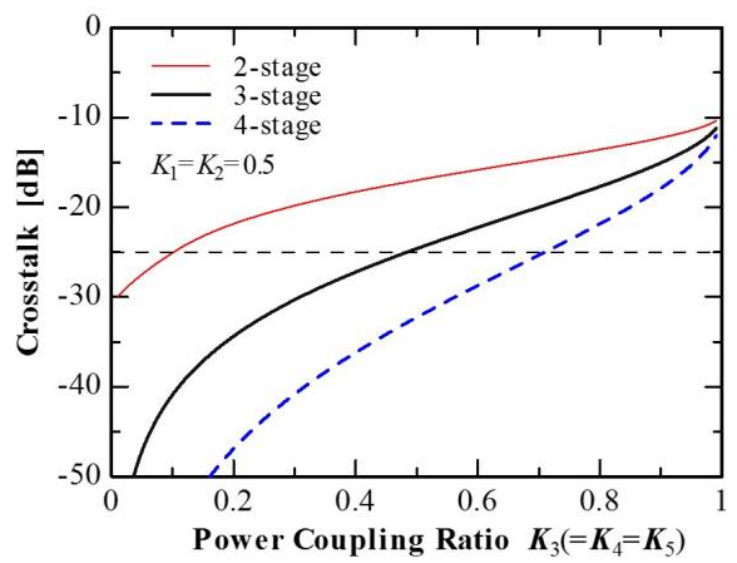

Figure 5. Dependence of Crosstalk on $K_{3}\left(=K_{4}=K_{5}\right)$ for $\alpha=0 \mathrm{~dB} / \mathrm{cm}$

\section{Spectrum characteristics}

General requirement for high-speed device is wide pass-band. The dependence of top passband width (at -1 $\mathrm{dB})$ on power coupling ratio $K_{3}\left(=K_{4}=K_{5}\right)$ for various stages is summarized in Figure 6 . This figure shows that wide pass-band can be realized by increasing value of $K_{3}\left(=K_{4}=K_{5}\right)$. Other parameters for evaluating the quality of spectra are ripple ratio and box-like spectrum. Ripple ratio should be as low as possible. The commercial value of ripple ratio is $<1 \mathrm{~dB}$. On the other hand, in order to express box-like spectrum, we introduce "shape factor" parameter, which defined as a ratio of bandwidth at $-1 \mathrm{~dB}$ and bandwidth at $-20 \mathrm{~dB}$. The ideal value of shape factor is 1 .

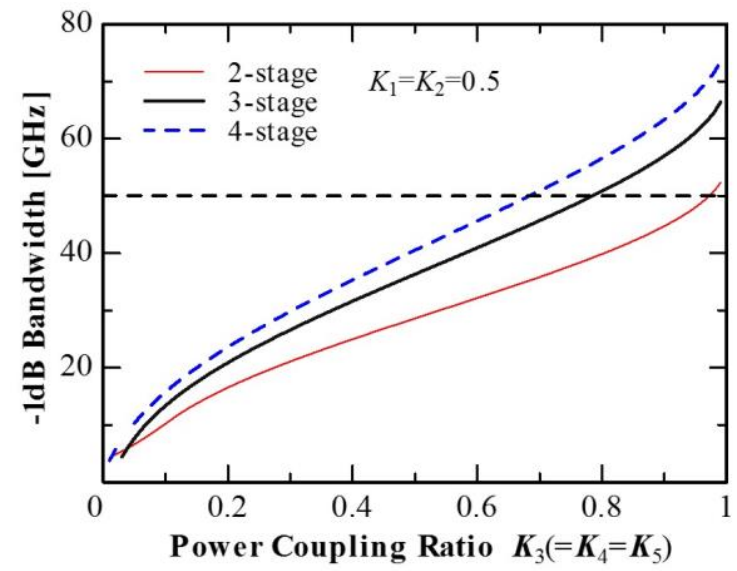

Figure 6. $-1 \mathrm{~dB}$ Bandwidth Characteristics Depending on Power Coupling Ratio $K_{3}\left(=K_{4}=K_{5}\right)$ for $\alpha=0 \mathrm{~dB} / \mathrm{cm}$

Figure 7 summarizes ripple ratio and shape factor characteristics depending on $K_{3}\left(=K_{4}=K_{5}\right)$. In general, ripple ratio increases with increasing $K_{3}\left(=K_{4}=K_{5}\right)$. However, for 4-stage structure, the ripple ratio degrades for $K_{3}<0.045$ and $K_{3}>0.13$. Since our target is to obtain wide pass-band with ripple ratio $<1 \mathrm{~dB}$, we obtain the values as follows: (1) $K_{3}<0.28$ for 2-stage structure; (2) $K_{3}\left(=K_{4}\right)<0.22$ for 3-stage structure; (3) $0.045<K_{3}\left(=K_{4}=K_{5}\right)<0.13$ for 4 -stage structure. 
Referring to the previous result at section 3.2 (crosstalk performance), although 4-stage has better performance on crosstalk, it does not provide better performance on bandwidth and ripple. As a result, it can be concluded that 3-stage cascade structure is the best choice for highspeed operation with low crosstalk and low ripple as summarized in Table 1. We also obtain that shape factor for 3-stage cascade at $K_{3}=K_{4}=0.22$ (the best choice for high operation) is 0.51 .

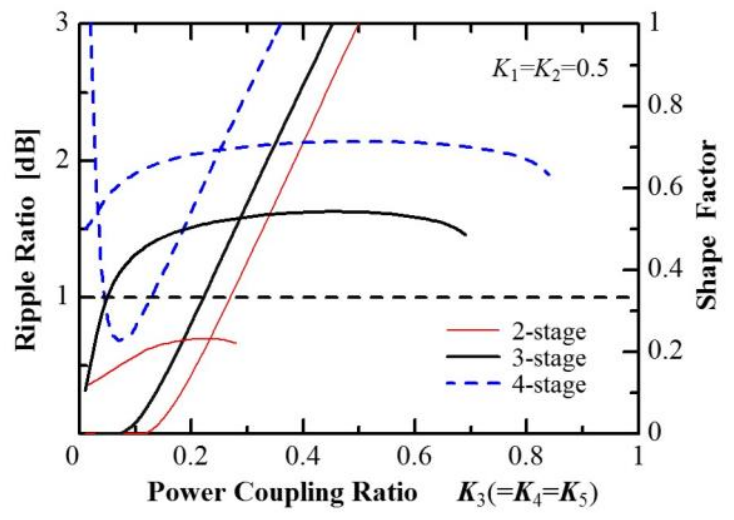

Figure.7. Ripple ratio and shape factor characteristics for $\alpha=0 \mathrm{~dB} / \mathrm{cm}$

TABLE 1. CROSSTALK AND MAXIMUM BANDWIDTH FOR 1DB RIPPLE REQUIREMENT.

\begin{tabular}{|c|c|c|c|}
\hline & $\begin{array}{c}\text { Power Coupling } \\
\text { Ratio }\end{array}$ & $\begin{array}{c}\text { Crosstalk } \\
(\mathbf{d B})\end{array}$ & $\begin{array}{c}\text { Max. Bandwidth } \\
\text { at -1 dB } \\
(\mathbf{G H z})\end{array}$ \\
\hline 2-stage & $K_{3}=0.28$ & -20 & 20 \\
\hline 3-stage & $K_{3}=K_{4}=0.22$ & -33 & 22 \\
\hline 4-stage & $K_{3}=K_{4}=K_{5}=0.13$ & -53 & 18 \\
\hline
\end{tabular}

\section{Effect of propagation loss}

Considering the loss effect is important to design optical devices. Recent optical waveguides, such as LN proton-exchange waveguide, have propagation loss below $1 \mathrm{~dB} / \mathrm{cm}$ [5]. Moreover, ring resonator has bending loss due to bending waveguide. By insertion various values of $\alpha$ in our analysis, the result shows that the performances of microring resonator degrade with increasing loss. Figure 8 shows degradation of crosstalk performance due to waveguide loss $\alpha$. The waveguide loss also affects to insertion loss of devices directly. Our calculation shows that in order to obtain insertion loss $<$ $2 \mathrm{~dB}$, waveguide loss is permitted up to $\sim 4 \mathrm{~dB} / \mathrm{cm}$ for $3-$ stage cascade. It means that general types of optical waveguides (LN, semiconductor or PLC) are available as cascaded micro-ring resonator.

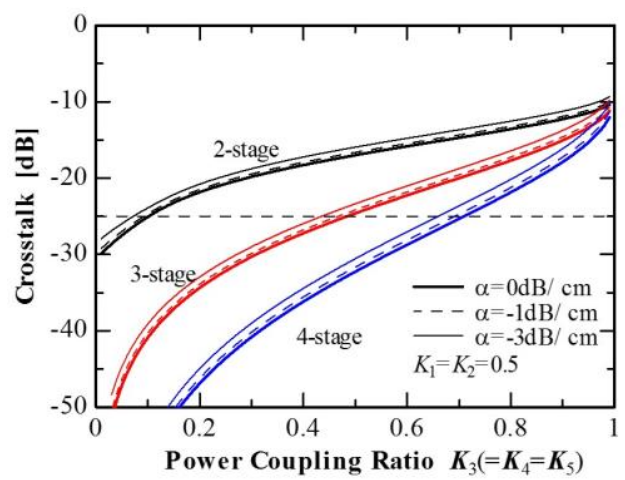

Figure 8. Crosstalk Characteristics for Various Changes of Loss.

\section{E. $1 \times 4$ Interleaver}

The results described above are based on $1 \times 2$ interleaver. In this section we will discuss availability of microring resonator for $1 \times 4$ interleaver. The schematic figure of $1 \times 4$ interleaver, which consists of 3 pairs of 3 stage cascaded microring resonator, is shown in Figure 9. In Table 1, it is shown that pass-band width of cascaded microring resonator is around $20 \mathrm{GHz}$. With this level of bandwidth, microring resonator is actually more reliable as $1 \times 4$ interleaver. For $100 \mathrm{GHz}-\mathrm{FSR}$ of microring, $1 \times 4$ interleaver works to split $25 \mathrm{GHz}$ channel spacing into $100 \mathrm{GHz}$ spacing. Basically, all characteristics evaluated at $1 \times 2$ interleaver do not change except crosstalk performance. We obtain that crosstalk of 3-stage cascade with the best performance described in Table 1 is $-24 \mathrm{~dB}$ for $1 \times 4$ interleaver.

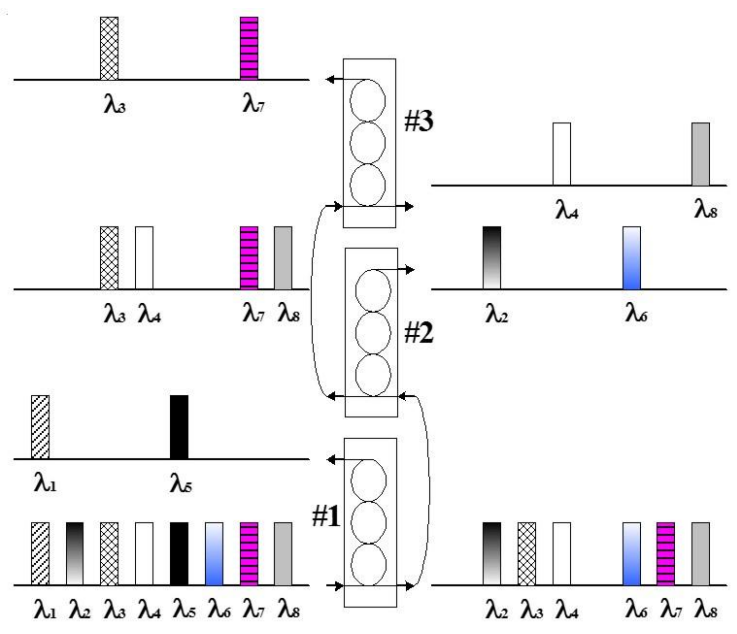

Figure 9. Schematic Diagram of $1 \times 4$ Interleaver Using 3 Pairs Cascaded Micro-ring Resonator.

\section{SUMMARIES}

Design of 3-stages Parallel Cascade Micro-ringResonator Type of Interleave Filter is investigated. 3stage cascade is the best choice for pass-band of 22 $\mathrm{GHz}$, ripple ratio $<1 \mathrm{~dB}$ and shape factor of 0.51 . The crosstalk of $1 \times 2$ interleaver is $-33 \mathrm{~dB}$, and $-24 \mathrm{~dB}$ for $1 \times 4$ interleaver. For the system permitting $2 \mathrm{~dB}$ insertion loss, all optical waveguides with loss $<4 \mathrm{~dB} / \mathrm{cm}$ are available to be realized as microring resonators. In the future, the results of this simulation, will be investigated and fabricated with different materials such as $\mathrm{SiO}_{2}$, Polymer.

\section{ACKNOWLEDGEMENT}

This research was supported by Research Center for Electronics and Telecommunication - Indonesian Institute of Sciences (PPET - LIPI) through DIPA Project funding.

\section{REFERENCES}

[1] M. Oguma, K. Jinguji, K. Kitoh, T. Shibata and A. Himeno, "Flat-passband interleave filter with $200 \mathrm{GHz}$ channel spacing based on planar lightwave circuit-type lattice structure", Elec. Lett., 36, pp.1299-2000, 2000

[2] D. Heard, "Tunable filter technology improves fiber optics and DWDMs", Europhotonics, pp. 44-45, June/July, 2000.

[3] B. E. Little, S. T. Chu, H. A. Haus, J. Foresi and J.P. Laine, "Microring resonator channel dropping filters", J. Lightwave Technol., 15, pp. pp.998-1005, 1997. 
[4] D. Mahmudin, T. T. Estu, P. Daud, N. Armi, Y. N. Wijayanto and G. Wiranto, "environmental liquid waste sensors using polymer multi-coupled ring resonators", in Proceedings of International Conference Smart Sensor and Application, May 2015.

[5] D. Mahmudin, T. T. Estu, P. Daud, I. D. P. Hermida, G. Sugandi and Y. N. Wijayanto, "Sensitivity improvement of multipath optical ring resonatore using silicon-on-insulator technology", in Proceedings of 10th IEEE Regional Symposium on Micro and Nanoelectronics (RSM), August 2015.
[6] K. Jinguji and M. Kawachi, "Synthesis of coherent two-port lattice-form optical delay line circuit", J. Lightwave Technol., 13, pp.73-82, 1995.

[7] J. Capmany and M. A. Muriel, "A new transfer matrix formalism for the analysis of fiber ring resonator: compound coupled structures for FDMA demultiplexing ", J. Lightwave Technol., 8, pp.1904-1919, 1990.

[8] H. Nishihara, M. Haruna and T. Suhara, Optical integrated circuits, London, UK: McGraw Hill, 1989, p.160. 